\title{
The operating schedule for battery energy storage companies in electricity market
}

\author{
Shengqi ZHANG ( $\square)$, Yateendra MISHRA, \\ Gerard LEDWICH, Yusheng XUE
}

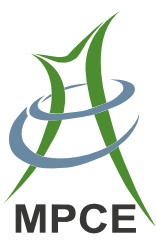

\begin{abstract}
This paper presents a series of operating schedules for Battery Energy Storage Companies (BESC) to provide peak shaving and spinning reserve services in the electricity markets under increasing wind penetration. As individual market participants, BESC can bid in ancillary services markets in an Independent System Operator (ISO) and contribute towards frequency and voltage support in the grid. Recent development in batteries technologies and availability of the day-ahead spot market prices would make BESC economically feasible. Profit maximization of BESC is achieved by determining the optimum capacity of Energy Storage Systems (ESS) required for meeting spinning reserve requirements as well as peak shaving. Historic spot market prices and frequency deviations from Australia Energy Market Operator (AEMO) are used for numerical simulations and the economic benefits of BESC is considered reflecting various aspects in Australia's National Electricity Markets (NEM).
\end{abstract}

Keywords Battery energy storage systems, Peak shaving, Spinning reserve, Energy market, Ancillary services market

Received: 28 August 2013/Accepted: 9 October 2013/Published online: 5 December 2013

(C) The Author(s) 2013. This article is published with open access at Springerlink.com

S. ZHANG, Y. MISHRA, G. LEDWICH, Queensland University

of Technology (QUT), Brisbane, Australia

$(\bowtie)$ e-mail: shengqi.zhang@student.qut.edu.au

Y. MISHRA

e-mail: yateendra.mishra@qut.edu.au

G. LEDWICH

e-mail: g.ledwich@qut.edu.au

Y. XUE, State Grid Electric Power Research Institute,

Nanjing, China

e-mail: xueyusheng@sgepri.sgcc.com.cn

\section{Introduction}

Since the introduction of intermittent renewable energy resources in the electricity markets, the role of energy storage is becoming increasing important for the reliable operation of electricity grid. Energy storage system (ESS) companies may enter the electricity market and act as a buffer between wholesale market and consumers. ESS can be widely used in power system applications ranging from providing high power to high energy output [1]. ESS can shift the energy from the off-peak time to the peak time to achieve peak shaving, as well as providing spinning reserve and consumption energy to achieve the frequency control.

There are many kinds of ESS, such as pumped storage plants, compressed air energy storage system and superconducting magnetic energy storage system. Recent developments in battery technology have resulted in Battery based ESS (BESS) as one of the mature and flexible ESS, which can achieve both peak shaving and frequency support. Frequency control and peak shaving are the two focal applications discussed in this paper.

As the day-ahead spot market prices are available in advance, it provides another opportunity for BESS companies to enter the electricity markets and provide ancillary service support in a cost effective way. Australia's National Electricity Market (NEM) is currently known as Australia Energy Market Operator (AEMO) and is responsible for the planning and operation of national electricity grid. The Queensland State electricity market is one part of AEMO and is used as a good annotation for the application of BESS for peak shaving where as whole of the Australia's NEM is considered for frequency support.

With the increasing demands of electricity energy and penetration of intermittent renewable source such as solar and wind, the usefulness of BESS in the modern electricity market cannot be overlooked [2]. Battery Energy Storage 


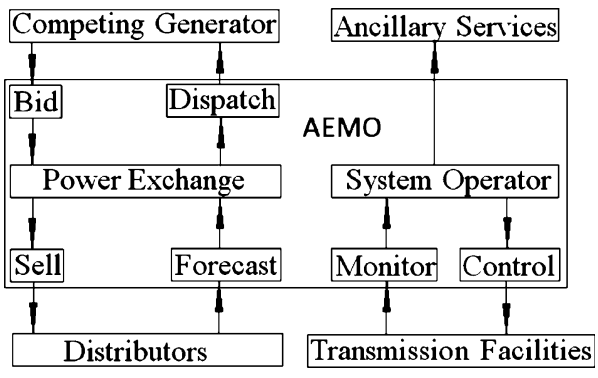

Fig. 1 The structure of the Australia's NEM

Companies (BESC), as additional electricity market participant, can get financial benefit by offering support for ancillary services.

This paper is laid out as follows: Section 2 gives a brief introduction of the Australian electricity market; and the BESS is introduced in Section 3. Furthermore, the operating schedule of BESC including numerical simulations for peak shaving and spinning reserve is explained in Sections 4 and 5 respectively. This is followed by conclusions in final section of the paper.

\section{Australia's national electricity market}

With the deregulation trend of the electricity market in modern power system, the electricity prices are set based on the bids received by suppliers (generators) and whole sale retailers or consumers (load). The whole sale electricity prices varies every half hour and is based on the new market clearing price set by AEMO [3]. The Australia's NEM [4] (Fig. 1) was established in December of the year 1998 including all the states of Australia except Tasmania which entered the NEM in the year 2005. AEMO is responsible for power system and electricity market of the whole Australia's NEM. In addition, at present, more than 90\% of Australia's electricity production still relies on the burning of fossil fuels, coal, gas and oil, but the capacity of renewable energy resources is increasing every year.

\subsection{Peak shaving in the energy market}

Under the national electricity rules, the wholesale trading in electricity is conducted as a spot market [4]. Therefore, a variety of forecasting processes are used to decide the demand level by AEMO. Demands are submitted every $5 \mathrm{~min}$, and then AMEO decides every dispatch price according to the suppliers' bids. In brief, the dispatch price presents the cost to supply the last megawatt of electricity of the demand, and the averaged every six dispatch prices are defined as one spot market price for that half hour. In NEM, half-hour is considered as one trading

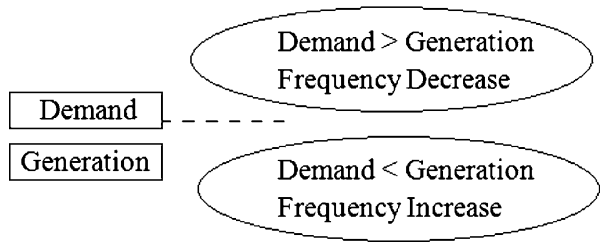

Fig. 2 The schedule of frequency control

interval and is different from most European and American countries. Moreover, the maximum and minimum of the market spot prices are set as $\$ 12,500$ and $-\$ 1,000$ respectively to limit the variation. The spot market prices spikes happen due to unexpected generation or transmission outages.

Load shifting is one way to delay few non essential loads to the off-peak time and reduce the spot market prices spikes. The application of BESS for peak shaving can achieved the load shifting function without shifting loads.

\subsection{Frequency regulation in ancillary service market}

Ancillary services are provided to control the key technical characteristics of power system such as frequency and voltage, through ancillary services market. In Australian ancillary services market (Fig. 1), there are three major categories: Frequency control ancillary services (FCAS), Network control ancillary services (NCAS), System restart ancillary services (SRAS) [5]. The bids of the ancillary services market are similar to the energy market, therefore, the costs of the ancillary services, depending on the quantity and the period, vary significantly. The participation in the ancillary service market is not limited to power plants only, but is also extended to load serving entities or retailers. ESS can also provide ancillary services for example frequency control. Frequency control [6] is the only service discussed in this paper, as BESS companies supply spinning reserve for the power system. The aim of frequency control is to maintain the balance between demand and generation as shown in Fig. 2.

In Australia, frequency control is separated into two parts which are regulation part and contingency part. The former part solves the minor deviations of frequency, while later part solves the major contingent events, for example, the loss of large generator. According AEMO standards, the frequency deviation must be brought back to its normal operating band within five minutes under any contingent event. Contingency may be incident involving loss of a transmission line, generator or load. Table 1 gives eight FCAS requirements in Australia's electricity market [5], which are similar to the primary frequency control, secondary control and tertiary control. Moreover, Control Performance Standards (CPS) which is set by NERC [7] is 
Table 1 FCAS requirements in 8 situations

\begin{tabular}{ll}
\hline Regulation & $\begin{array}{l}\text { Regulation raise } \\
\text { Regulation lower }\end{array}$ \\
Contingency & $\begin{array}{l}\text { Fast raise and fast lower (6 s response to arrest the } \\
\text { frequency deviation) } \\
\text { Slow raise and slow lower (60 s response to keep the } \\
\text { frequency within the single contingency band) } \\
\text { Delayed raise and delayed lower (5 min response to } \\
\text { retune the frequency back to the normal operating } \\
\text { band) }\end{array}$ \\
\hline
\end{tabular}

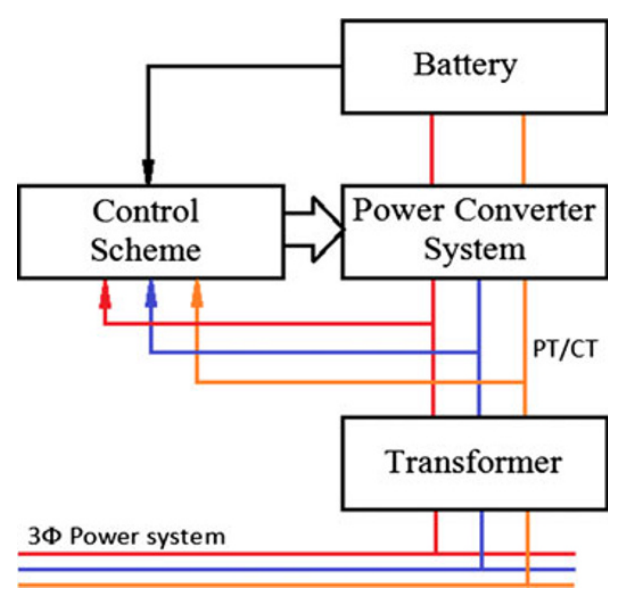

Fig. 3 The structure of BESS

also another standard to evaluate the performance of system frequency.

\section{Battery energy storage systems (BESS)}

The structure of BESS including a power conversion system connecting the battery pack to 3-phase AC system can be summarized in Fig. 3 [8].

Although there are many different types of BESS systems available in the market, there are 3 types of BESS namely lead-acid, nickel-cadmium and vanadium redox flow that are prominent for large scale deployment and hence are considered in this paper. The former two batteries are cell batteries. Lead-acid BESS is considered as the most mature battery technology, whereas vanadium redox flow BESS is the most mature flow batteries as of today. The three BESS types are introduced briefly as follows.

Lead-acid BESS Lead-acid battery is the most popular battery when compared with any other traditional batteries. The fundamental parts of the lead-acid battery include battery cells and a dilute solution of sulfuric acid in water electrolyte [9]. The lead-acid BESS have already used in practice in many countries. Indeed the greatest strengths of this BESS are high degree of maturity and low capital cost. However, the drawback of lead-acid battery is its limited lifespan.

Nickel-cadmium BESS Nickel-cadmium (NiCd) battery is another kind of mature battery technology. It has good cycle life performance and high efficiency [10]. There are several places where NiCd battery is being used in grid application in the USA. Even the European plane maker has acknowledge the safety feature of NiCd Battery systems and have announced to replace the former $\mathrm{Li}$-ion battery with NiCd battery in all Air bus A380.

Vanadium redox flow BESS The basic structure of the redox flow battery contains two separate tanks [11] filled with solution. The detailed working principle is beyond the scope of this paper and only advantages of the vanadiumredox flow battery are listed. Firstly, the capacity of the battery can be large or small, depending on the application. Secondly, the response time of the battery is faster. Vanadium-redox flow battery is safer to use with no environmental concerns. Compared with the former two battery types, VRF batteries can provide higher power output in the shorter period of time [12].

\section{Application of BESS for peak shaving}

Mainly BESS used for end-user peak shaving is located not far from the energy consumers, such as heavy industrials or large business places. The optimization model used for identifying the capacity and utilization of BESS for peak shaving purpose is described below:

\subsection{The optimization model for peak shaving using BESS}

In general, the models of electricity energy charged and discharged in different BESS are in the similar way [13] and can be expresses as using (1) and (2). When BESS is being charged at the hour $t$,

$W_{t+1}=W_{t}+\eta_{\mathrm{c}} P_{t}^{+} \times(1 \mathrm{~h})$

and when BESS is being discharged at the hour $t$,

$W_{t+1}=W_{t}+\eta_{\mathrm{d}} P_{t}^{-} \times(1 \mathrm{~h})$

where $W_{t}, W_{t+1}$, are the electricity stored in BESS at hour $t$ and $t+1 ; P_{t}$ is the output power of BESS at time $t$, which is positive in (1) and is negative in (2); and $\eta_{\mathrm{c}}$ and $\eta_{\mathrm{d}}$ are charging efficiency and discharging efficiency of BESS respectively. Generally, discharging efficiency is higher than charging efficiency.

The operation model of BESS can be represented by (1) and (2), whereas the economic model including cost and payback period can be calculated using (3)-(7). The capital 
cost and operation and maintenance cost (O\&M) of BESS are calculated as in (3) and (4) respectively.

$C_{\text {capital }}=C_{\mathrm{p}} P_{\max }+C_{\mathrm{W}} W_{\max }$

$C_{\mathrm{O \& M}}=\left(C_{\mathrm{Mf}} P_{\max }+C_{\mathrm{Wv}} W_{\max }\right)$

where $P_{\max }$ is the power output of BESS; $W_{\max }$ is the energy capacity of BESS. The units of $C_{\mathrm{p}}$ and $C_{\mathrm{W}}$ are $\$ / \mathrm{kW}$ and $\$ / \mathrm{kWh}$ respectively, and the units of $C_{\mathrm{Mf}}$ and $C_{\mathrm{Wv}}$ are $\$ / \mathrm{kW} /$ year and $\$ / \mathrm{kWh} /$ year. Moreover, the payback period can be calculated as in (5).

$\sum_{N=1}^{\mathrm{PP}} \frac{R_{\text {annual }}}{(1+r)^{N}} \geq C_{\text {capital }}+C_{\mathrm{O} \& \mathrm{M}}$

where $P_{\mathrm{P}}$ is the abbreviation of the payback period; $R_{\text {annual }}$ is the annual revenue of BESS, and $r$ is the discount rate. The discount rate is assumed to keep constant in the payback period. As the right side of (5) is the sum of the geometric progression, it can be used to calculate the payback period as shown in (6) below.

$N \leq \frac{\log \left[1-\frac{\left(C_{\text {capital }}+C_{\mathrm{O} \& \mathrm{M}}\right)(1-Q)}{Q R_{\text {annual }}}\right]}{\log Q}$

$Q=\frac{1}{1+r}$

The O\&M cost is far less than the capital cost of BESS and hence is ignored in this study.

The profit for BESC is expressed as (8), and can be considered as the objective function of BESS formulation model.

$\operatorname{Max}(C)=\operatorname{Max}\left(\sum_{1}^{48} P_{t} \times S_{\mathrm{P} t}\right)$

where $C$ is the cost which can be saved by the application of BESS; $P_{t}$ is the charging/discharging power at time interval $t$; and $S_{\mathrm{P} t}$ is the spot market prices at interval $t$.

There are also few limitations/constraints of BESS and can be summarized as follows in (9) and (10).

$-P_{\max } \leq P_{t} \leq P_{\max }$

$0 \leq W_{t} \leq W_{\max }$

$P_{\max }$ is the maximal output of BESS and $W_{\max }$ is the maximal capacity of BESS and are same as in (3) and (4).

Maximizing the value of the objective function as in (8) is entirely up to the BESS user and therefore can be considered as an optimization problem. The objective function in (8) varies due to variability of $P_{t}$ i.e. when the sign of $P_{t}$ changes, the efficiency coefficients also changes. Moreover, $W_{1}$ can be assumed to be zero at the beginning, but $W_{48}$ cannot be guaranteed to be zero after one day, which means $W_{1}$ of the next day may not be zero. There have been plenty of approaches proposed in the past to solve this problem including dynamic programming, nonlinear programming, multipass iteration particle swarm optimization approach and Quasi-Newton updating method [14]. In this paper, linear programming is used by modifying the matrix of the parameters $P_{t}$ and $W_{t}$. The Matlab Optimization Toolbox is used for simulation studies presented in this paper. Furthermore, it is important to highlight the key assumptions made in this study and are summarized below:

1) Firstly, 48 intervals of spot market prices are available in one day advance, so $24 \mathrm{~h}$ is considered as one optimization cycle. In other words, the power stored in BESS in a day should be almost utilized in the same day and very little or no power should be available after $24 \mathrm{~h}$.

2) Secondly, the energy stored in BESS is zero at the beginning of the simulation.

3) The efficiencies of different battery types are similar and can be assumed same for this higher level studies. The discharging and charging efficiencies keep constant as 0.95 and 0.65 separately.

4) Finally, compared with the total demand, the capacity of BESS is small. Therefore the spot market prices are assumed to remain unchanged due to BESS operation.

\subsection{Simulations and results}

The four different daily cases of the year 2012 in the state of Queensland are chosen to show the optimal peak shaving strategy. The economic analysis is performed to evaluate the feasibility of different BESS types.

\subsubsection{Optimal peak shaving strategy}

Optimal peak shaving strategy remains unchanged for different types of BESS technology. The spot market prices of four days picked from the summer, winder, typical weekday and weekends in a year in Australia and the corresponding operation of BESS is shown here in Figs. 4-11.

Summer weekday A typical summer weekday has one distinct spot market energy price spike at around 16:30 $\mathrm{h}$ as shown in Fig. 4. Moreover, the electricity prices are lower in the morning time from 3:00 $\mathrm{h}$ to $6: 00 \mathrm{~h}$. The BESS is charged in the early morning and discharged in the late afternoon, corresponding to the spot market prices as shown in Fig. 5. The energy stored in BESS is nearly zero at the end of the cycle making sure that the energy stored in $24 \mathrm{~h}$ is consumed with in a day.

Winter weekday There are two spot market energy price spikes in the winter weekday as shown in Fig. 6. Therefore, 


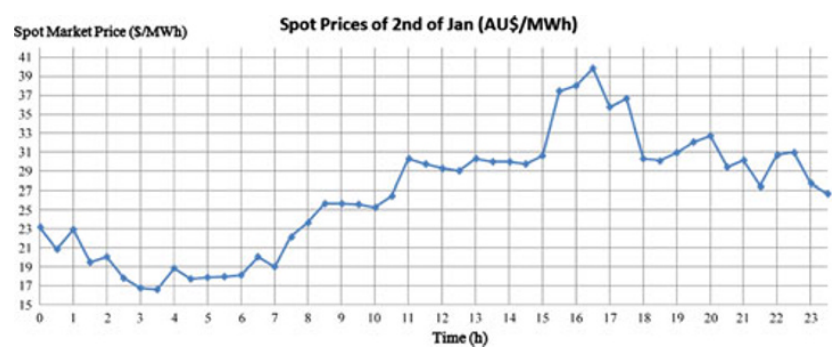

Fig. 4 The spot market price in a summer weekday

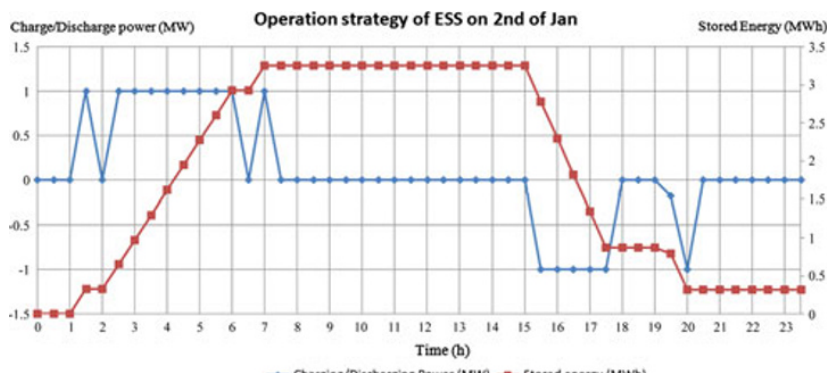

Fig. 5 The charging/discharging and power stored energy of BESS in the summer weekday (the blue line is the output power and the red line is stored energy)

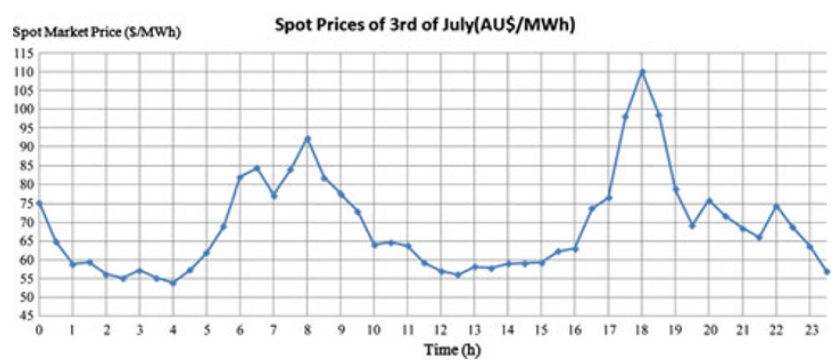

Fig. 6 The spot market price in a winter weekday

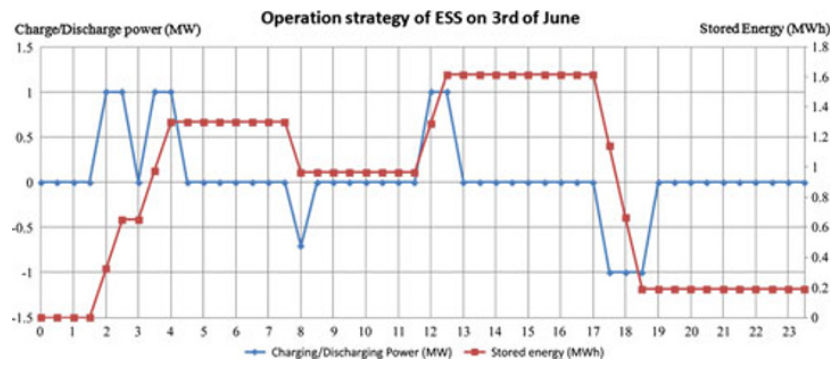

Fig. 7 The charging/discharging and power stored energy of BESS in the winter weekday (the blue line is the output power and the red line is stored energy)

BESS is discharged during the time 8:00am and 17:30pm18:30pm, shown as Fig. 7. In addition, the variation of spot market prices in winter is larger than in summer in weekdays. The peak BESS capacity utilized in summer is about

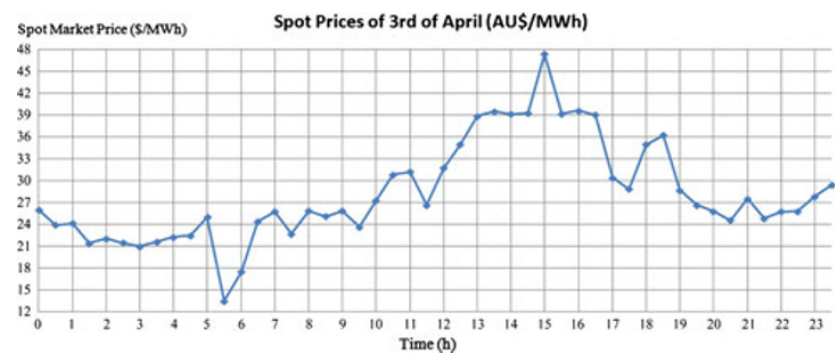

Fig. 8 The spot market price of a typical weekday

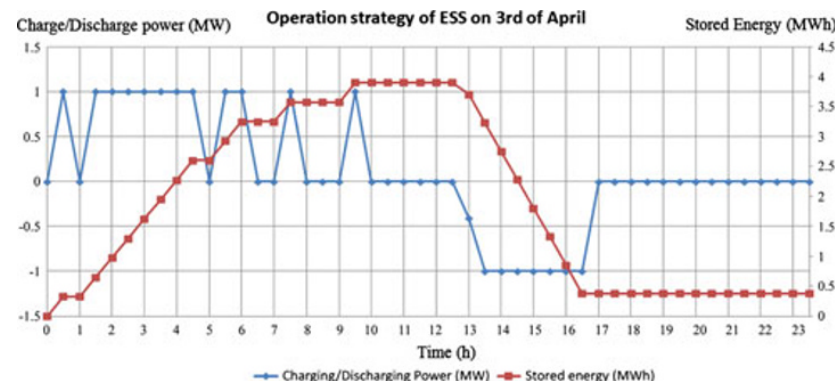

Fig. 9 The charging/discharging and power stored energy of BESS in one weekday (the blue line is the output power and the red line is stored energy)

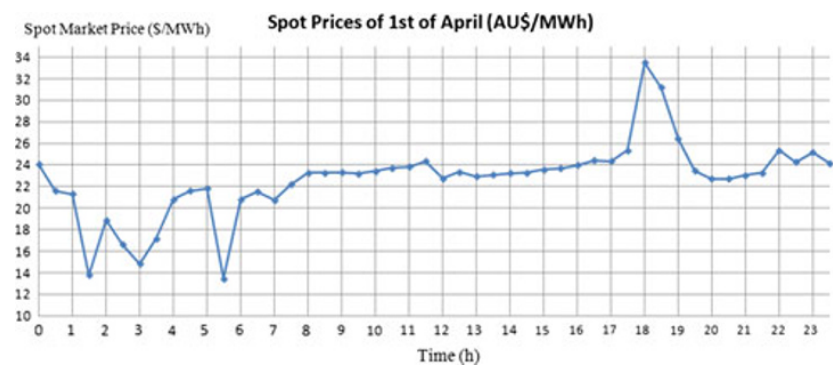

Fig. 10 The spot market price of a typical weekend

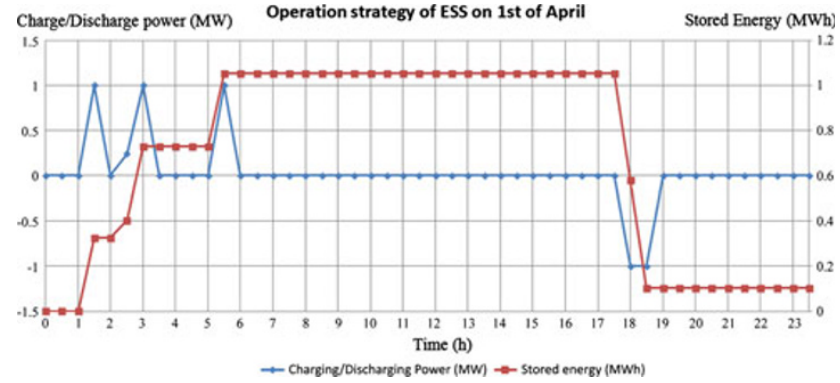

Fig. 11 The charging/discharging and power stored energy of BESS in one weekend (the blue line is the output power and the red line is stored energy)

3.4 MWh (red line in Fig. 5) which is larger than 1.6 MWh (red line in Fig. 7) in winter.

Typical weekdays and weekends The situations of the weekday (Fig. 8 and blue line of Fig. 9) and weekend 
(Fig. 10 and blue line of Fig. 11) are shown in these four figures. It is obvious that the spot market prices are higher in weekdays than in weekends, and the maximum capacities of BESS used in weekday and weekend are about $4 \mathrm{MWh}$ (red line in Fig. 9) and 1.1 MWh (red line in Fig. 11) separately. According to the trends of the spot market prices, the results are reasonable, because BESS is charged when the spot market prices are low, while it is discharged when the prices are high.

From the four cases above, the optimal peak shaving strategy of BESS can be adopted for the real electricity market. BESC could earn profit by entering the energy market.

\subsubsection{Economic analysis}

The cost saved by BESS for the month of January of 2012 is shown in Fig. 12 based on the spot market price for that month. The discharging and charging efficiencies are assumed as 0.95 and 0.65 respectively. It is observed that savings are high on few days due to spikes in the spot market prices. In other words, the more fluctuant the market prices are, the more cost can be saved by BESS.

Furthermore, the economic analysis of three types of BESS is performed. BESC would like to do this analysis to weigh in pros and cons of various BESS types and may prefer one or other types as appropriate. The values of parameters of capital costs, charging / discharging efficiencies are shown in Table 2. The profits of every month by using three kinds of BESS are shown separately in Table 3 . Table 4 illustrates the annual revenue, the capital cost and the payback period of different BESS types. The capital cost of lead-acid type BESS is the lowest and generates highest revenue. Therefore, the payback period of lead-acid type BESS is the shortest. On the contrary, the lifespan of the Lead-acid is almost half compared to any other batteries types. The problem is that the lifespan of the lead-acid battery may shorter than the payback period. The revenue of the $\mathrm{NiCd}$ is also high, the payback period is 17 years. However, the lifespan of $\mathrm{NiCd}$ battery is much longer.

The economic analysis here is just an indicative comparison as the cost of different BESS are decreasing

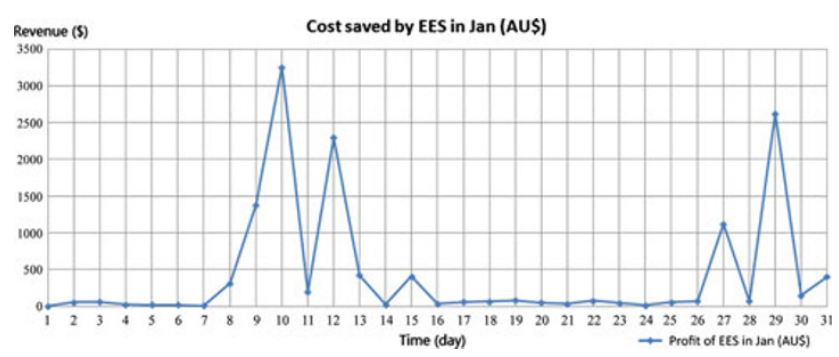

Fig. 12 The cost saved by BESS for the month of January
Table 2 Parameters for different kind of batteries

\begin{tabular}{lccr}
\hline Parameter & Lead-acid & NiCd & VRF \\
\hline Capital cost 1 (\$/kWh) & 275 & 330 & 426 \\
Charging efficiency (\%) & 80 & 74 & 77 \\
Discharging efficiency (\%) & 99 & 98 & 98 \\
\hline
\end{tabular}

Table 3 The revenue of different types of BESS

\begin{tabular}{lrrr}
\hline Month & Lead-acid $(\$)$ & $\mathrm{NiCd}(\$)$ & $\mathrm{VRF}(\$)$ \\
\hline January & $15,740.0$ & $15,126.0$ & $15,466.0$ \\
February & $8,703.2$ & $8,190.0$ & $8,474.4$ \\
March & $8,191.9$ & $7,737.1$ & $7,989.5$ \\
April & $2,177.4$ & $1,655.6$ & $1,938.2$ \\
May & $1,826.1$ & $1,399.2$ & $1,632.5$ \\
June & $4,849.5$ & $3,960.0$ & $4,454.7$ \\
July & $7,206.9$ & $5,757.7$ & $6,534.7$ \\
August & $9,043.9$ & $8,235.6$ & $8,651.5$ \\
September & $4,848.6$ & $4,238.2$ & $4,552.9$ \\
October & $3,009.8$ & $2,428.6$ & $2,728.1$ \\
November & $3,659.6$ & $3,295.5$ & $3,468.8$ \\
December & $1,333.4$ & $1,271.2$ & $1,303.0$ \\
Total & $70,590.3$ & $63,294.7$ & $67,194.3$ \\
\hline
\end{tabular}

Table 4 The annual revenue, capital cost and payback period of BESS

\begin{tabular}{lccc}
\hline Parameter & Lead-acid (\$) & NiCd (\$) & VRF (\$) \\
\hline $\mathrm{R}_{\text {annual }}(\$)$ & $70,590.3$ & $63,294.7$ & $67,194.3$ \\
$\mathrm{C}_{\text {captical }}(\$)$ & 598,000 & 717,000 & 926,000 \\
$P_{\mathrm{P}}$ (year) & 12 & 17 & 24 \\
\hline
\end{tabular}

dramatically over the last few years and is expected to decrease further due to technological advancement and economy of scale.

\section{Application of BESS for spinning reserve}

\subsection{The model of spinning reserve with BESS}

Power produced should be instantly consumed in the power system to maintain the nominal system frequency. Any contingency such as loss of generation or sudden increase in the load would disturb the steady state and frequency will deviate from the nominal value. Spinning reserve has been traditionally deployed in the power system to maintain the balance error between generation and load demand.

The ancillary services market does provide a mechanism to support the spinning reserve in the power systems 
through various bids. The nominal frequency of the system in Australia is $50 \mathrm{~Hz}$. It is accepted that frequency is around $50 \mathrm{~Hz}$, and the allowable range of errors is defined as non-critical window, which means that no additional action is required if the frequency deviation is within the noncritical window. For example, if the noncritical window is from -0.02 to $+0.02 \mathrm{~Hz}$, BESS is discharged when the frequency values are below $49.98 \mathrm{~Hz}$, while BESS is charged when the frequency values are above the $50.02 \mathrm{~Hz}$, according to the signals from the controller/ operator.

The main aim of the operation schedule of BESS is to determine the minimum possible capacity required for the ancillary service market. In the model of spinning reserve with BESS, the recharging power and the size of noncritical window are two influencing factors of the BESS capacity. Figure 13 shows the measured frequency values of the mainland of Australia from AEMO, including one generation event at the time $15: 26 \mathrm{~h}$ [15]. The power-frequency characteristic [16] of the frequency controller follows the principles shown in Fig. 14. The relationship between the power of BESS and the frequency deviation is linear outside the non-critical window. The output power of

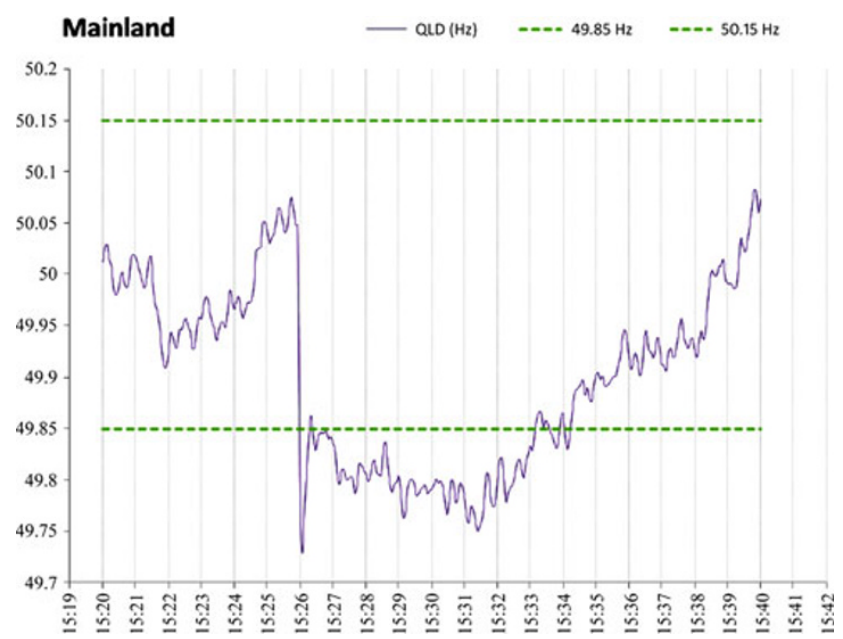

Fig.13 One example of frequency curve of Australian mainland

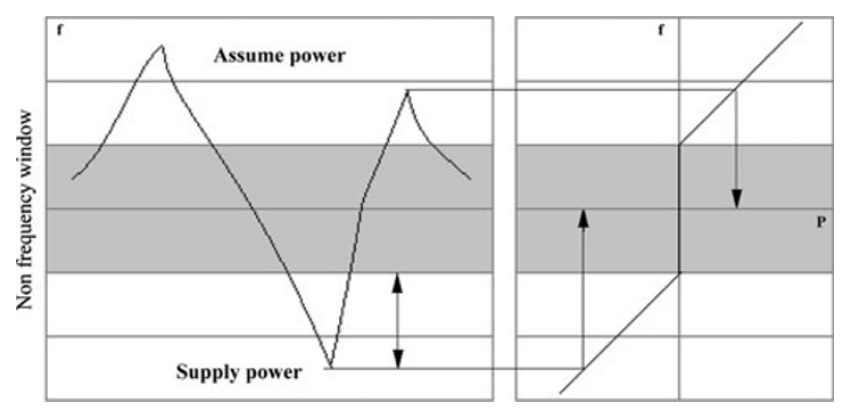

Fig. 14 Power-frequency characteristics of BESS [16]
BESS is kept at zero or a constant number during the noncritical window.

The complete operating schedule of BESS to provide the spinning reserve for frequency regulation is shown as follows.

For BESS company:

1) Decide $f_{\text {lower }}$ under the rule of local ISO company and the optimization model;

2) BESS is discharged when

$$
\begin{aligned}
& -f_{\text {lower }}<f<-f_{\text {non-critical }} \\
& P_{\text {Discharging }}=\alpha \Delta f
\end{aligned}
$$

3) BESS is charged when

$$
\begin{aligned}
& f_{\text {non-critical }}<f<f_{\text {upper }} \\
& P_{\text {Charging }}=\beta \cdot \Delta f
\end{aligned}
$$

4) BESS is recharged when

$$
\begin{aligned}
& |\Delta f|<f_{\text {non-critical }} \\
& P_{\text {Recharging }}=\gamma \% \cdot f_{\text {rated }}
\end{aligned}
$$

where $f_{\text {upper }}$ is the max number of frequency band decided by ISO company; $f_{\text {lower }}$ is less than $f_{\text {upper }}$ decided by BESS company; $f_{\text {non-critical }}$ is the parameter of non-critical window, which is decided by ISO company, and is assumed as $0.02 \mathrm{~Hz}$; charging and discharging rate coefficients, i.e. $\alpha$ and $\beta$ are assumed as the same value as $2.5 ; f_{\text {rated }}$ is the rated value.

For ISO company:

1) Decide the maximum value of non-critical window;

2) Decide the ancillary services prices according to the spinning reserve and capacity of BESS.

\subsection{Simulations and results}

As the data released by AEMO, the system frequency lies within 49.85 to $50.15 \mathrm{~Hz}$ for $99.96 \%$ of the time. The standard deviation of past 13 months of mainland region of Australia is shown in Fig. 15 [15]. In 2012, 99\% of the frequency values of mainland region are located within 49.92 to $50.06 \mathrm{~Hz}$. And greater than $99.99 \%$ frequency values are within 49.75 to $50.15 \mathrm{~Hz}$.

Therefore, the non-critical window can start from $0.02 \mathrm{~Hz}$, and the upper frequency band can be fixed as $0.15 \mathrm{~Hz}$. Furthermore, the rated power value of BESS is chosen as $2 \mathrm{MW}$, which is only a small part of total spinning reserve. Consequently, the influence of frequency when BESS is recharged during the non-critical window is neglected.

Based on the former two assumptions, 120 random frequency values are assumed in Fig. 16. The $y$-axis is the 


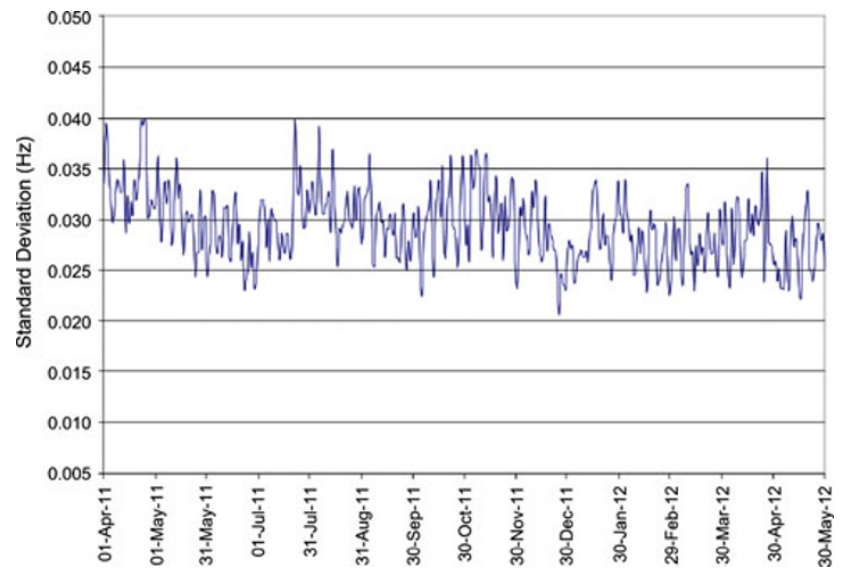

Fig.15 Daily standard deviation of mainland frequency

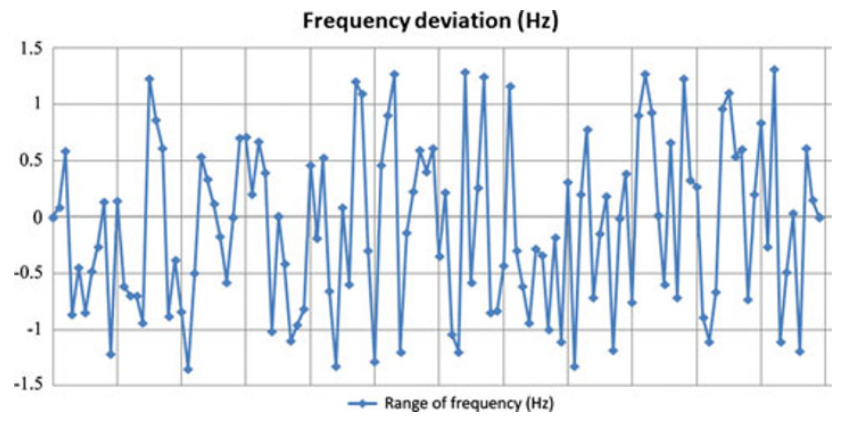

Fig. 16 The frequency deviations for $120 \mathrm{~s}$

frequency deviations. According to the real situations, except a fewer points are located in non-critical window, more points values are less than 0 . Therefore, the power of recharging rate is used to make up the difference capacity between charging periods and discharging periods. The power of recharging rate is about $1 \%$ of rated power values.

1) BESS operating schedule for frequency support

As motioned before, two influencing factors, i.e. the size of non-critical window and the recharging rate $(\gamma)$ will be discussed here separately.

BESS start from partly charged situation which is set as zero, and the non-critical window is kept fixed as $0.02 \mathrm{~Hz}$. The required capacities are shown in Fig. 17. The $y$-axis represents the required capacity of BESS in MWh.

In Fig. 17, the different colours of each line show the required capacity for different recharging rate $(\gamma)$. In detail, as the recharging power increases, the required capacity of BESS decreases at the beginning, but the required capacity increases after a particular point. In order to find the optimal required capacity of BESS, Fig. 18 is obtained by increasing recharging rate $(\gamma)$ step by step. $1 \%$ of rated value is the best recharging power in this situation.

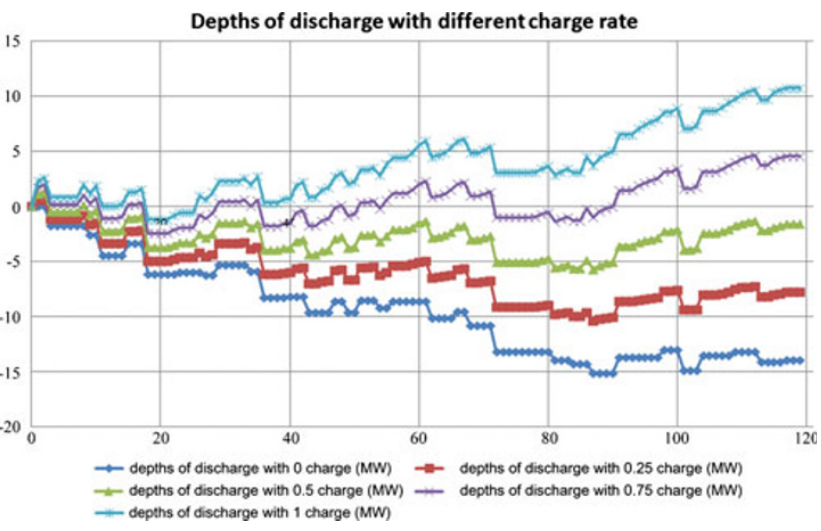

Fig. 17 The required capacity of BESS in different recharging rate

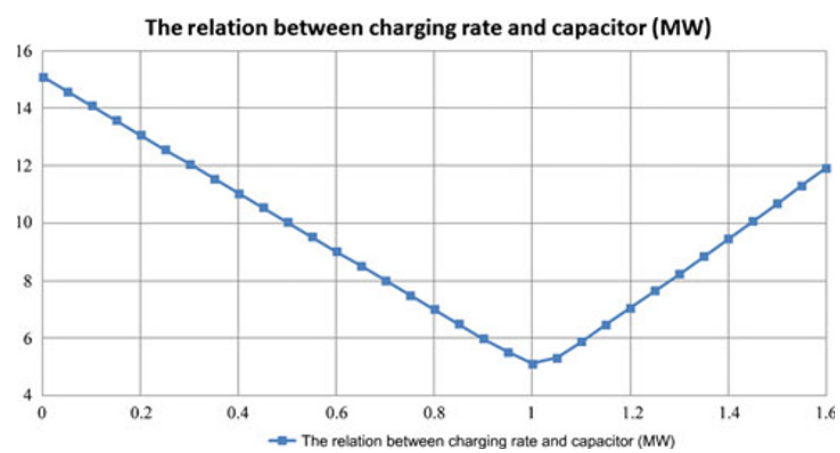

Fig.18 The capacities of BESS in different recharging rate

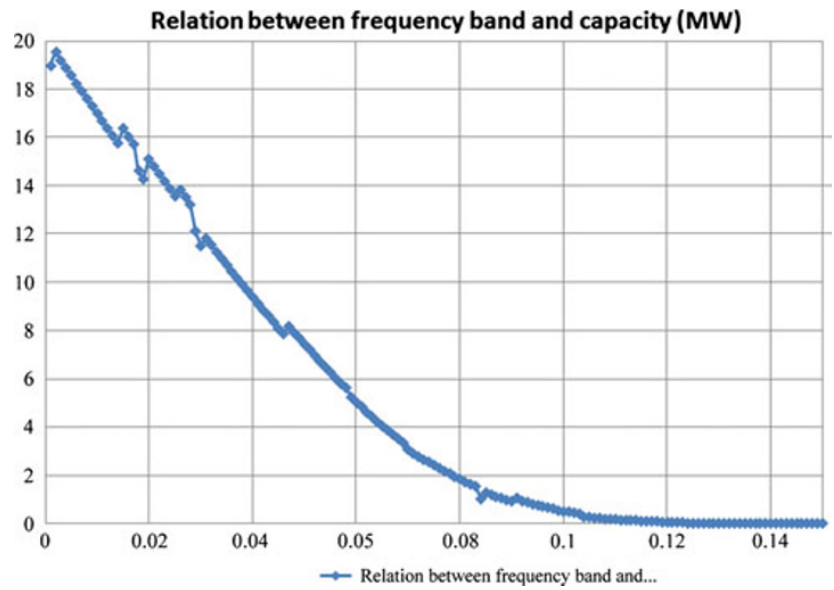

Fig. 19 The capacities of BESS in different non-critical windows

The non-critical window which is another influencing factor varies from 0.002 to $0.15 \mathrm{~Hz}$, and the corresponding capacity of BESS keeps decreasing from 20 to $0 \mathrm{MWh}$ as shown in Fig. 19. The $x$-axis shows the increasing values of non-critical windows in $\mathrm{Hz}$, and the $y$-axis represents the capacity of BESS in MWh. In conclusion, the smaller the non-critical window, the larger the BESS capacity required for frequency support. 


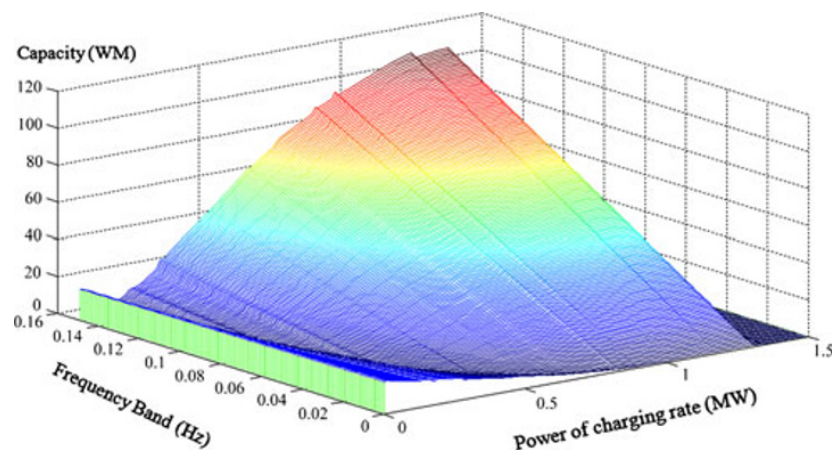

Fig. 20 3D graph for capacity, recharging power and frequency band

At last, In Fig. 20, hundreds of pairs of non-critical window ( $x$-axis) and recharging rates $(y$-axis $\gamma \%)$ are plotted to find the optimal capacity of BESS. For a specific frequency band of say $0.04 \mathrm{~Hz}$ and recharging rate $(\gamma \%)$ as 0.5 , the BESS capacity is determined to be $8.4 \mathrm{MWh}$.

\section{2) Proposed operation of BESS for frequency support}

The possible practical schedule enables the interaction between ISO Company and BESCs through ancillary services market. For each day, ISO Company can decide the non-critical frequency window as per the predicted performance of the power system for that day. This depends on the amount of renewables committed depending on the weather forecast of that day. At the same time, BESC decides their non-critical frequency window and recharging rate $(\gamma \%)$ according to their capacity. The larger the capacity of BESS, the smaller the non-critical window they can offer.

Briefly, to encourage BESC to installing capacities of batteries in relatively large quantities, ISO could provide some economic stimulation as following.

$P_{\mathrm{b}}=P_{\mathrm{c}}+k\left(f_{\text {upper }}-f_{\text {non-critical }}\right)$

where $P_{\mathrm{b}}$ is the price ISO buy energy from BESC; $P_{\mathrm{c}}$ is the price ISO buy energy from conventional generations.

In this case, the more obligations BESC undertake more profit they can get. Furthermore, BESC can install a larger system with the same pay-back period.

\section{Conclusions}

Recent development in batteries technologies are driving the cost of BESS down. Availability of day ahead spot market prices in energy market and the provision of ancillary services market, BESC can be established to join the electricity market and get profit.

This paper provides two simple optimal operating strategies for BESS in both energy market and ancillary services market. Those two strategies can be achieved in the electricity markets. The economic benefit is another major consideration for BESS companies entering in the electricity market. Historic spot market prices and frequency deviations from Australia Energy Market Operator (AEMO) are used for the profit maximization of BESC. Optimum capacity of ESS required for meeting spinning reserve requirements and to achieve desired peak shaving is investigated in Australia's national electricity market (NEM).

Compared with the conventional generation which is used as spinning reserve, BESS is more expensive. However, environmental concerns such as $\mathrm{CO}_{2}$ emissions and associate government policies such as carbon tax have resulted in unprecedented growth of renewable energy sources. The intermittent nature of renewables such as wind and solar introduces power system operational challenges and hence requires additional spinning reserves to maintain adequate performance. BESS have flexible capacities and can be used to enhance and assist renewable energy penetration in the modern electricity grid.

The control system of BESS and the location of BESS would be the part of future research.

Open Access This article is distributed under the terms of the Creative Commons Attribution License which permits any use, distribution, and reproduction in any medium, provided the original author(s) and the source are credited.

\section{References}

[1] Parker CD (2001) Lead-acid battery energy-storage systems for electricity supply networks. J Power Sources 100(1/2):18-28, 30

[2] Daneshfar F, Bevrani H (2010) Load-frequency control: a GAbased multi-agent reinforcement learning. IET Gener Transm Dis 4(1):13-26

[3] Rebours YG, Kirschen DS, Trotignon M et al (2007) A survey of frequency and voltage control ancillary services-part II: economic features. IEEE Trans Power Syst 22(1):358-366

[4] An introduction to Australia's national electricity market. Australian Energy Market Operator (AEMO), 2010

[5] Guide to ancillary services in the national electricity market, ed 01. Australian Energy Market Operator(AEMO), 2010

[6] Bevrania H, Ledwichb G, Dongc ZY (2009) Regional frequency response analysis under normal and emergency conditions. Electr Power Syst Res 79(5):837-845

[7] Wanga C, McCalleyc JD (2013) Impact of wind power on control performance standards. Int J Electr Power Energy Syst 47:225-234

[8] Kottick D, Blau M, Edelstein D (1993) Battery energy storage for frequency regulation in an Island power system. IEEE Trans Energ Convers 8(3):455-459

[9] Coppez G, Chowdhury S, Chowdhury SP (2010) Impacts of energy storage in distributed power generation: a review. In: Proceedings of the 2010 international conference on power system technology (POWERCON'10), Hangzhou, China, 24-28 Oct 2010, 7 p

[10] Oudalov A, Chartouni D, Ohler C, et al (2006) Value analysis of battery energy storage applications in power systems. In: 
Proceedings of the IEEE PES power systems conference and exposition (PSCE'06), Atlanta, GA, USA, 29 Oct-1 Nov 2006, pp 2206-2211

[11] Zhang X, Wei Y, Xu S, et al (2010) Optimization design of allvanadium redox flow battery energy storage system. In: Proceedings of the 2010 China international conference on electricity distribution (CICED'10), Nanjing, China, 13-16 Sept 2010, 4 p

[12] Banham-Hall DD, Taylor GA, Smith CA, et al (2011) Frequency control using vanadium redox flow batteries on wind farms. In: Proceedings of the power and energy society general meeting, Detroit, MI, USA, 24-29 Jul 2011, 8 p

[13] Chacra FA, Bastard P, Fleury G et al (2005) Impact of energy storage costs on economical performance in a distribution substation. IEEE Trans Power Syst 20(2):684-691

[14] Hu W, Chen Z, Bak-Jensen B (2010) Optimal operation strategy of battery energy storage system to real-time electricity price in Denmark. In: Proceedings of the power and energy society general meeting, Minneapolis, MN, USA, 25-29 Jul 2010, 7 p

[15] Power system frequency and time error monitoring, ed 5. Australian Energy Market Operator (AEMO), 2012

[16] Oudalov A, Chartouni D, Ohler C (2007) Optimizing a battery energy storage system for primary frequency control. IEEE Trans Power Syst 22(3):1259-1266

\section{Author Biographies}

Shengqi ZHANG received the B.E. degree from Southeast University, Nanjing, Jiangsu, China, in 2010, the M. Eng degree from the University of Queensland, Brisbane, Queensland, Australia, in 2012, current $\mathrm{Ph} . \mathrm{D}$. candidate at Queensland University of Technology (QUT).

Yateendra MISHRA received the Ph.D. degree from the University of Queensland, Brisbane, Qld., Australia, in 2009. He was a visiting Scholar in the University of Tennessee, Knoxville in 2009. Before joining QUT as a lecturer in July 2011, he worked as a Transmission Planning Engineer at Midwest ISO, Carmel, IN for 2.5 years. He is a member of IEEE and CIGRE. His current research interests include distributed generation and distributed energy storage, power system stability and control and their applications in Smart Grid.

Gerard LEDWICH received the Ph.D. degree in electrical engineering from the University of Newcastle, Newcastle, Australia, in 1976. He has been a Chair Professor in Electrical Asset Management at Queensland University of Technology (QUT), Brisbane, Qld., Australia, since 1998. He was the Head of Electrical Engineering at the University of Newcastle from 1997 to 1998, and was previously associated with the University of Queensland from 1976 to 1994. His interests are in the areas of power systems, power electronics, and controls. Dr. Ledwich is a Fellow of I.E. Australia.

Yusheng XUE received MSEE degree from EPRI China in 1981 and $\mathrm{PhD}$ degree from the University of Liege, Belgium in 1987. He became a Member of Chinese Academy of Engineering in 1995. He has been the Chief Engineer at the Nanjing Automation Research Institute (NARI), China since 1993, and the Chief Editor of three Chinese journals. He is a member of the specialist team of State Grid Corporation of China and that of China Southern Power Grid. He also holds the positions of Adjunct Professor in 14 universities in China. $\mathrm{He}$ is Committee Member of the CSEE and CIGRE. His research interests are mainly in power system stability and automation. 